\title{
Application of 3-D Parallel Electrical Technology Detecting the Water-Rich Areas
}

\author{
Xuan Wang, Liquan Guo \\ School of Earth and Environment, Anhui University of Science and Technology, Huainan, China \\ Email: qulanzhai@126.com
}

Received 25 August 2014; revised 20 September 2014; accepted 15 October 2014

Copyright (C) 2014 by authors and Scientific Research Publishing Inc.

This work is licensed under the Creative Commons Attribution International License (CC BY). http://creativecommons.org/licenses/by/4.0/

c) (i) Open Access

\begin{abstract}
Coal working face is damaged more and more seriously by water below the coal face floor. Therefore, floor water detection is a must in the process of extraction. This article aims to introducing application and principle of the two-gateways parallel 3-D electrical technology and the arrangement of the observation system. The authors use this method to detect the water under the floor of a mine in north of Anhui. The results show that the two-gateways parallel 3-D electrical technology can accurately locate the water-rich areas, providing the basis for drilling drainage and grouting construction.
\end{abstract}

\section{Keywords}

The Two-Gateways Parallel 3-D Electrical Technology, Coal Face Floor, Water-Rich Areas

\section{Introduction}

Coal working face is threatened increasingly by water beneath the coal face floor along with the mining depth. So the water detection of working face is particularly important [1] [2]. Currently, the main methods of water detection in coal mining face are the transient electromagnetic method, the audio-frequency electrical penetration technique and the two-gateways parallel 3-D electrical technology [3]-[5]. Among them, the two-gateways parallel 3-D electrical technology is widely used due to its effective penetrability. Response features of water bearing anomalous body between the seepage field and the geoelectric field were obtained and were applied to establish the variation relationship between the water ponding boundary and the resistivity in order to delineate and analyze the water ponding scope in the goaf of the mine [6]. Based on the electrical property differences between water-rich area and normal strata, the capable resitivity images of water-rich area were analyzed in detail. In addition to the known data such as those of geology, water inflow of boreholes, grouting, the property and distribution ranger of water-rich could be well found [7]. This paper mainly uses the 3-D parallel electrical 
technology to detect the water under the floor of a mine in north of Anhui.

\section{The Principle of Detecting Method}

\subsection{The Two-Gateways Parallel 3-D Electrical Technology}

The parallel electrical technology was first proposed by Anhui University of Science and Technology [8]. And it was verified in a large number of the models and field tests. This method achieved significant effect [9] [10]. The observation system of the two-gateways parallel 3-D electrical technology depends on the roadways. Usually electrical lines are laid along the air roadway (the roadway of F) and the conveyor roadway (the roadway of $\mathrm{J}$ ) in the roadway floor. At the same time, the power supply electrode B is placed in the opposite lane corresponding (Figure 1), and plus 1 infinite electrode N. The parallel electrical instrument is used in data collection. It is applied to observe the changes of underground space electric field surrounding each electrode in the line. When one electrode is powered, the remaining electrodes simultaneously measure the potential changes of natural electric field, the first field and the second field. The multiple coverage greatly improves the detecting accuracy. When a station data acquisition is completed, back line is moved to the next station data acquisition while covering a certain area of the former station until the whole detection task is finished.

\subsection{Data Acquisition Technology}

Depending on the different arrangements of electrodes, the data acquisition of the parallel electrical technology works in two ways: single point power field (AM) and opposite electric field power supply (ABM).

1) Operating mode of AM

In AM acquisition, the opposite electrode $\mathrm{B}$ is arranged in the position corresponding in the oppositional roadway. Each electrode in the line combining B pole supplies power once, at the same time the other electrodes in the line are collecting the electric field data. Through the professional software decoding, we can get the data of the double-pole device, the three-pole device and the composite profiling device in the resistivity profile method. The potential field it measures is a point electric field (Figure 2). The method is suitable for long line detection task on account of its single point of power supply, fast data acquisition and greatly-improved working efficiency.

2) Operating mode of $A B M$

The observation system of ABM is similar to that of AM. The only difference is that ABM works in a way that two electrodes supply power, while the other electrodes collect data synchronically. Via the parallel elec-

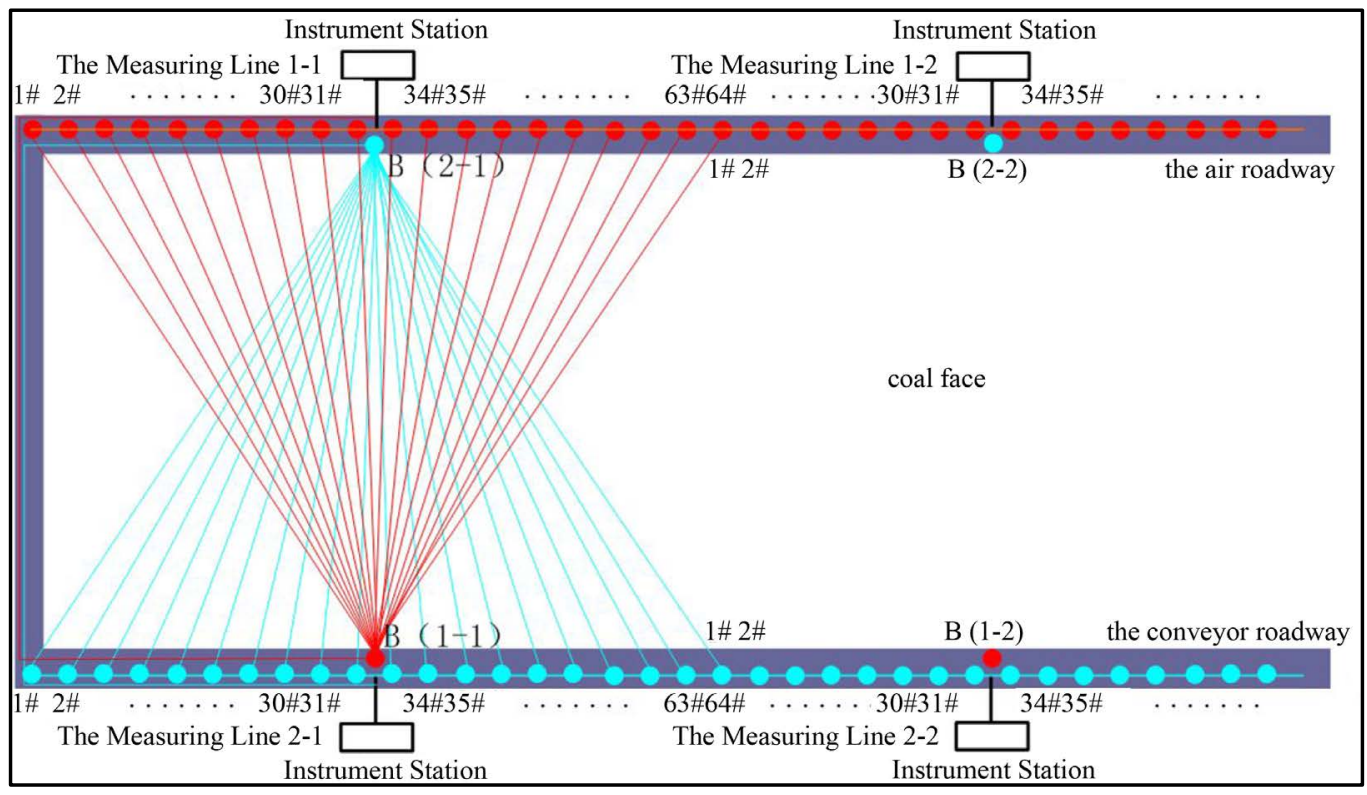

Figure 1. The observation system of the two-gateways parallel 3-D electrical technology. 


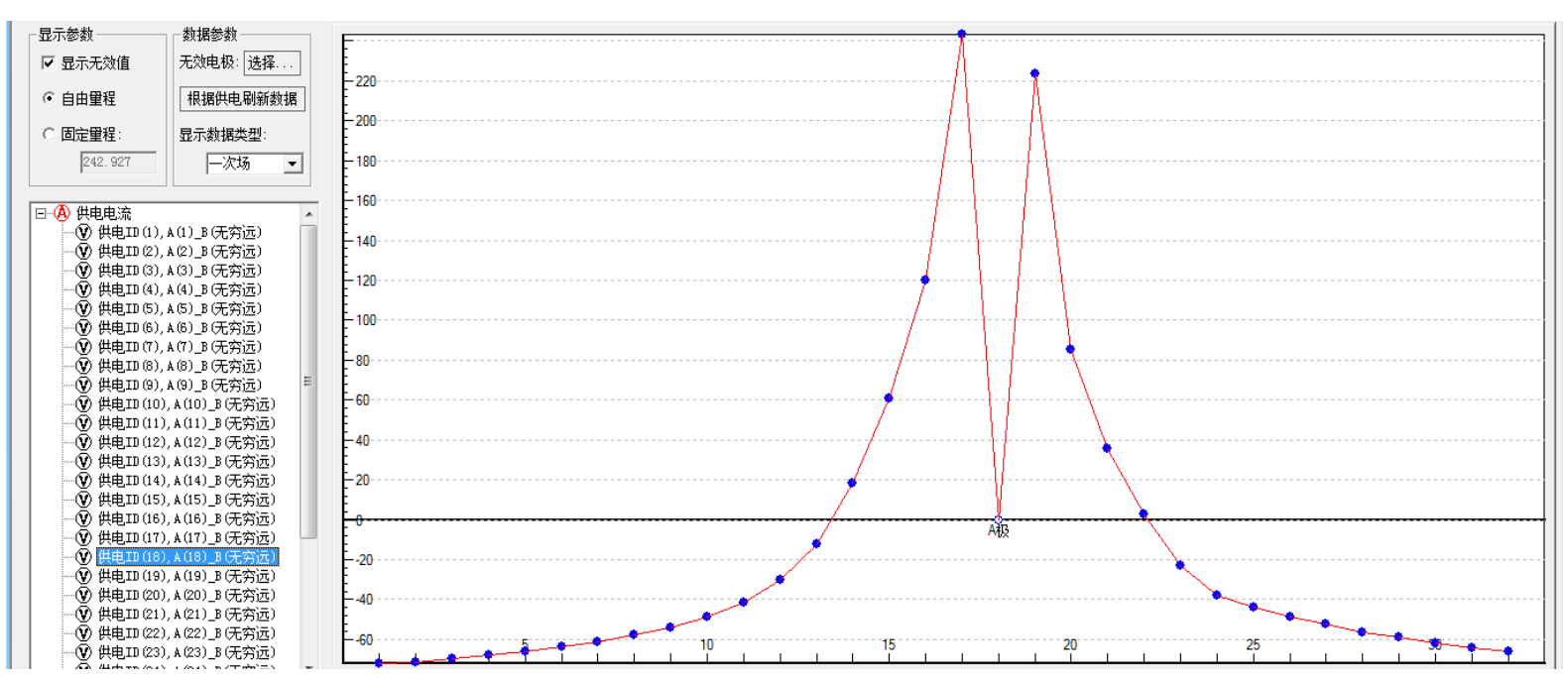

Figure 2. Distribution of AM voltage measurement.

trical collection system, a measurement can achieve the effect of all kinds of four-pole device of high density electrical prospecting, which improves the collection efficiency highly, reduces the system error, and acquires plenty of data. Compared with the AM method, ABM takes longer to get the results but more precisely. The ABM method of data collection is a dual specific point source electric field (Figure 3).

\subsection{Three Dimensional Inversion}

The data of the parallel electrical technology is inversion by the professional soft-ware AGI. The data collected by the two-gateways parallel 3-D electrical technology is decoded and extracted to getting different devices' currents and potential data. Typically, the currents and potential data will be combined and used 3-D resistivity inversion. The general form of 3-D resistivity inversion problem is expressed as:

$$
\Delta d=G \Delta m
$$

In the equation: $G$ is a Jacobi matrix; $\Delta d$ is the difference between the observed data of $d$ and the residual vector forward theoretical value of $d_{0}$. For the three-dimensional problem, the model is divided into three dimensional grids, and the parameters of each grid cell are the conductivity values. At the same time the observation data of 3-D inversion is a measurement of the potential difference. Because of the large variation, logarithm is used to calibrate the inversion data and model parameters in order to ensure the stability of inversion. AGI inversion will provide the resistivity profile in the region, and analyzing the resistivity profile can locate the water-rich areas, which is the basis for the coal mine drainage and grouting engineering.

\section{Detection Applications}

\subsection{General Situation of Working Face}

The mine in the North-Anhui for the test, its 1018 main seam is 10 coal seam, which is in the middle of Shanxi Formation. The seam is $75.5 \mathrm{~cm}$ below the $\mathrm{Al}$ mudstones, $50.79 \mathrm{~cm}$ average above Taiyuan Formation first Limestone. Its floor thickness is $4.65-5.36 \mathrm{~cm}, 4.76 \mathrm{~cm}$ in average, variation coefficient $\gamma=24 \%$, workability in$\operatorname{dex} \mathrm{K}=1$, dip $5^{\circ}-15^{\circ}$ (average dip $12^{\circ}$ ). It is estimated that the floor is threaten by limestone water of coal mine floor, so the hydrogeology condition should be researched before the extraction. This operation detects the strata aquosity under the floor of working face using the two-gateways parallel 3-D electrical technology to determine the water-rich areas of coal face floor accurately, to guide drilling surveying, releasing water and grouting work, and to ensure the safety of the working face extraction.

\subsection{Analysis of Detection Results}

The data of the two-gateways parallel 3-D electrical technology method are decoded by AGI inversion software to invert the resistivity profile (Figure 4). The diagram indicates 6 low resistivity abnormal areas in the working 


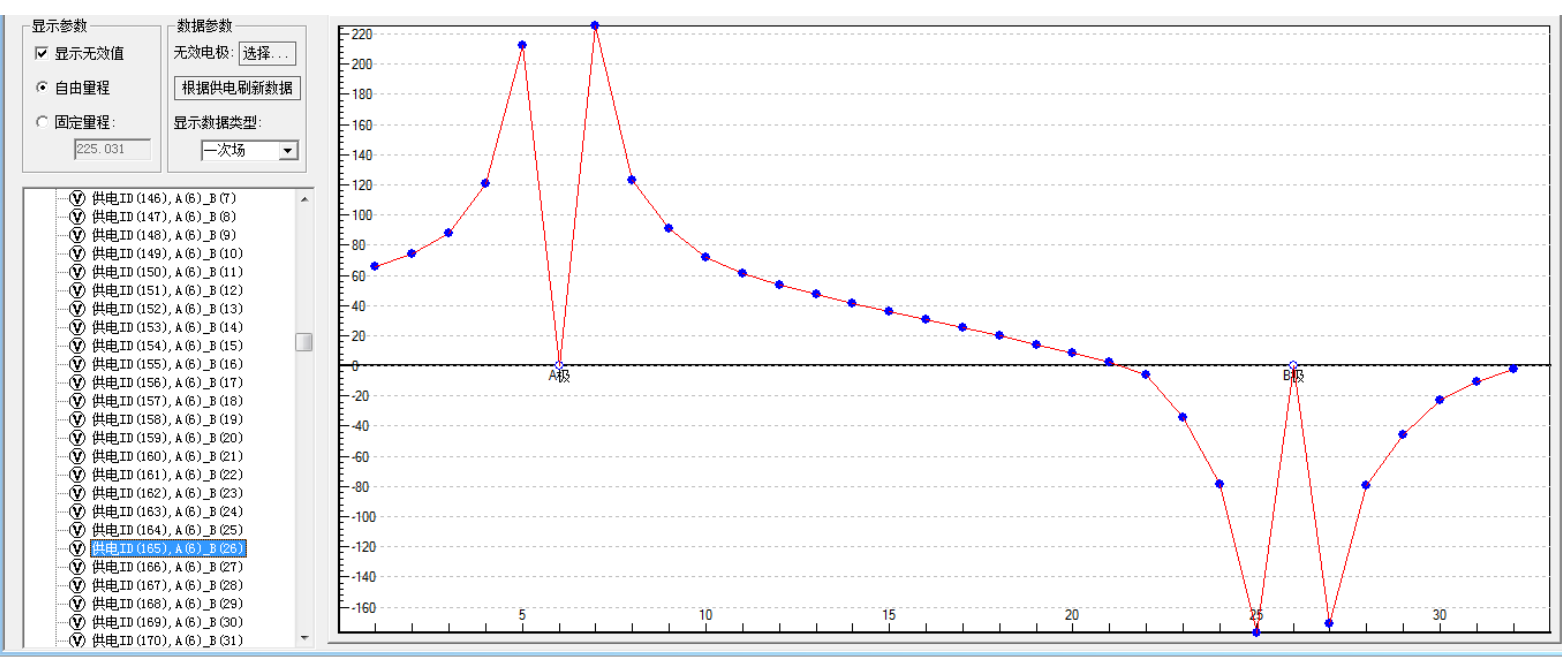

Figure 3. Distribution of ABM voltage measurement.

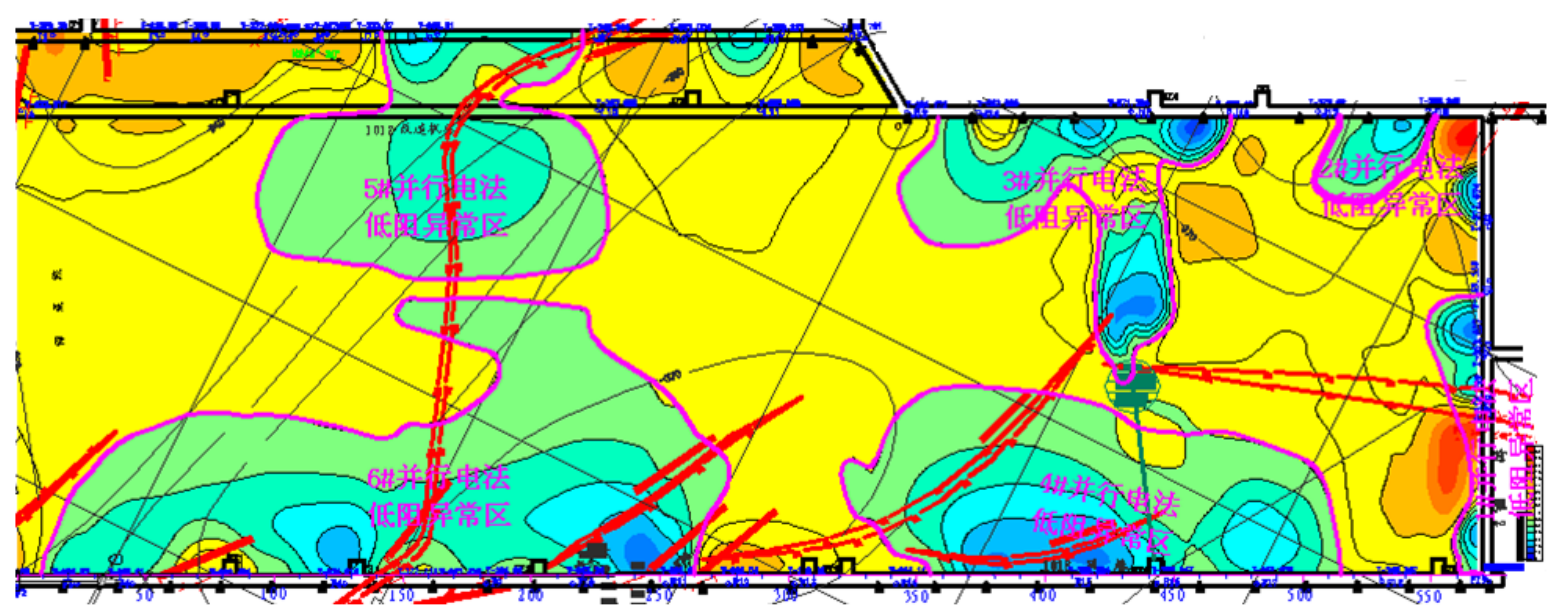

Figure 4. The water detection result of 1018 working surface floor.

face floor. The rest are all above $40 \Omega \cdot m$. In the low resistivity areas, 4 stretch widely to the floor and face except that $1 \#$ and 2\# are low and outskirt of roadways. $40 \Omega \cdot m$ is the dividing line of high and low resistivity: 30 - $40 \Omega \cdot m$ indicates water-bearing area; less than $30 \Omega \cdot m$ indicates water-rich area. As a result, the low resistivity is a big threat to working floor extraction.

\subsection{Test Results and Analysis}

To cope with the 6 low resistivity abnormal areas, mine workers implemented lots of drilling grouting, The water hole position, water yield, and grout amount of the detection area shows that achieves great effects.

Figure 5 is drilling water yield and grouting consumption statistics distribution map. The resistivity picture before grouting shows that the resistivity of abnormal area $1,2,3$ is $\rho_{\mathrm{s} 1}=35 \Omega \cdot m, \rho_{\mathrm{s} 2}=25 \Omega \cdot m, \rho_{\mathrm{s} 3}=25$ $\Omega \cdot m$ respectively; the inflow of abnormal area $1,2,3$ is $Q_{i 1}=14 \mathrm{~m}^{3} / \mathrm{h}, \mathrm{Q}_{\mathrm{i} 2}=44 \mathrm{~m}^{3} / \mathrm{h}, \mathrm{Q}_{\mathrm{i} 3}=10 \mathrm{~m}^{3} / \mathrm{h}$ respectively; and the grouting amount of abnormal area $1,2,3$ is $\mathrm{Q}_{\mathrm{g} 1}=100 \mathrm{~m}^{3}, \mathrm{Q}_{\mathrm{g} 2}=600 \mathrm{~m}^{3}, \mathrm{Q}_{\mathrm{g} 3}=200 \mathrm{~m}^{3}$ respectively. As can be seen, the areas of low resistivity before grouting are consistent with the results of the water inflow and the grouting. That is low resistivity abnormal area in the detection indicates rich water in the calcareous rock floor, so the grouting quantity should be high values too.

\section{Conclusions}

1) The two-gateway parallel 3-D electrical technology can accurately locate the water-rich areas, providing 


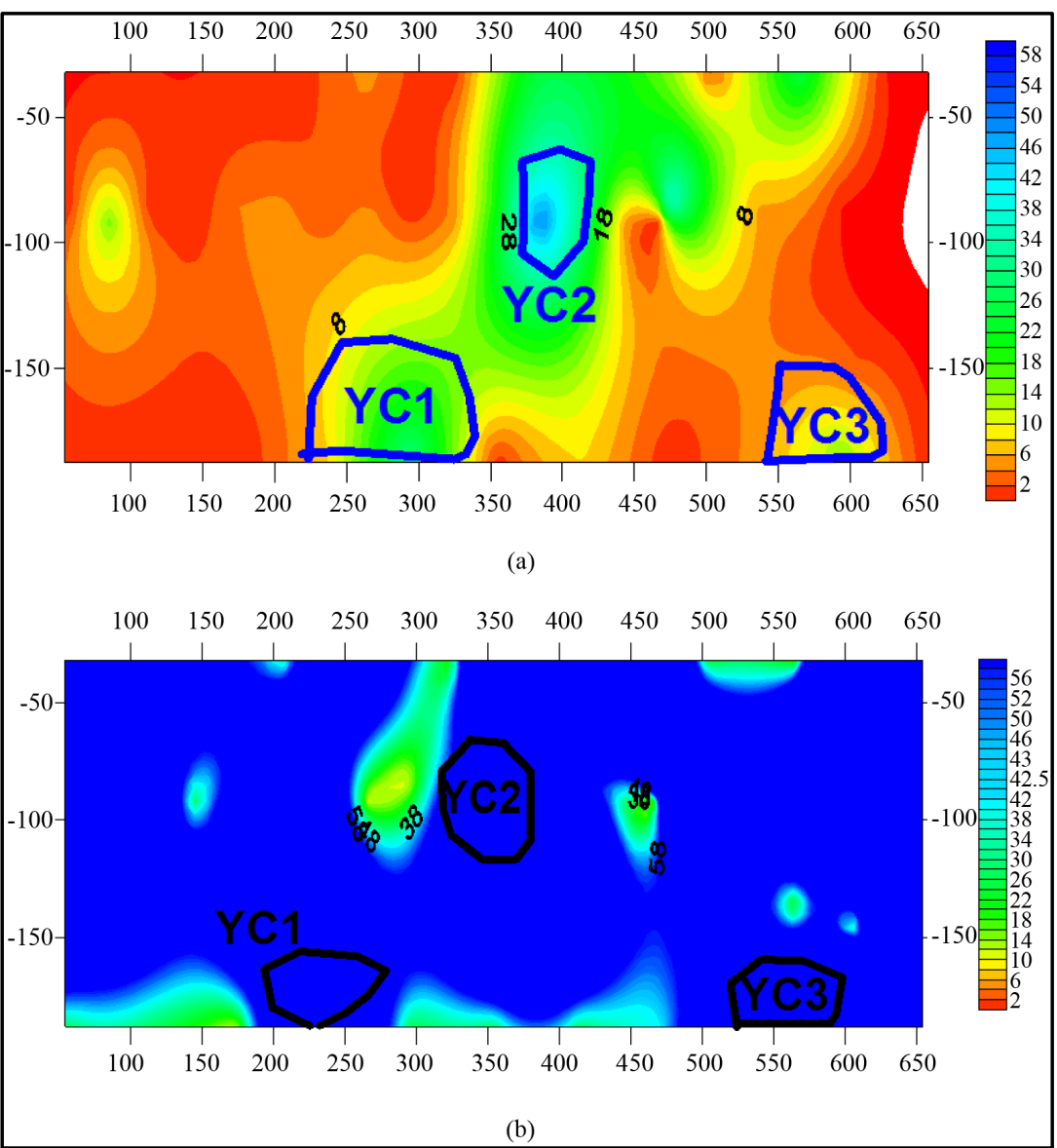

Figure 5. The distribution of drilling water yield and grouting consumption statistics. (a) Distribution of inflow water. (b) Distribution of grouting.

the basis for drilling drainage and grouting construction.

2) By the two-gateway parallel 3-D detection technologies, grouting is indirectly evaluated thus preventing water inrush effectively in the extraction.

\section{References}

[1] Fu, M.R., Han, D.Y. and Zhang, P.S. (2013) A Comparative Testing Study of the Methods for Detecting the FloorWater Hazard in the Working Face of a Mine. Geophysical and Geochemical Exploration, 37, 1067-1070.

[2] Fu, M.R., Zhang, P.S. and Wang, D.S. (2013) Study on Integrated Detection Techniques for Face Floor Water Hazards. Mining Safety and Environmental Protection, 40, 92-95.

[3] Fan, J., Zhang, P.S. and Wu, R.X. (2014) Three-Dimensional Electrical Detection of Water Abundance in Floor Rock Stratum of Coal Seam with Large Dip Angle. Mining Safety and Environmental Protection, 41, 54-56.

[4] Yu, J.C., Hu, B. and Liu, Z.Q. (2011) The Application of Mine Transient Electromagnetic Detection Technology. Geophysical and Geochemical Exploration, 35, 532-535.

[5] Zeng, F.L., Wang, Y.S. and Zhang, X.H. (1997) Mine Voice Frequency Electric Perspective Technique and Its Application. Coal Geology and Exploration, 6, 54-57.

[6] Wu, C.F., Liu, S.D., Qiu, Z.L. and Yang, S.L. (2013) Technology of Network Parallel Electric Method Applied to Detection of Water Ponding in Mining Goaf. Coal Science and Technology, 41, 93-95.

[7] Wu, R.X., Liu, S.D. and Zhang, P.S. (2010) The Exploration of Two-Gateroaway Sparallel 3-D Electrical Technology for Water-Rich Area with in Coal Face Floor. Journal of China Coal Society, 35, 454-457.

[8] Liu, S.D. and Zhang, P.S. (2004) The Signal Acquisition Method of Electrode Potential Difference in the Distributed Paralleling in Tellective Way. China Patent: zl 200410014020.0. 
[9] Fu, M.R. (2013) Study on Two-Gateways 3-D Electrical Technology for Water Abundance within Mine Working Face Floor. Master's Thesis, Anhui University of Science and Technology, Hefei.

[10] Liu, S.D., Wu, R.X. and Zhang, P.S. (2009) Three-Dimensional Parallel Electric Surveying and Its Applications in Water Disaster Exploration in Coalmines. Journal of China Coal Society, 34, 927-932. 
Scientific Research Publishing (SCIRP) is one of the largest Open Access journal publishers. It is currently publishing more than 200 open access, online, peer-reviewed journals covering a wide range of academic disciplines. SCIRP serves the worldwide academic communities and contributes to the progress and application of science with its publication.

Other selected journals from SCIRP are listed as below. Submit your manuscript to us via either submit@scirp.org or Online Submission Portal.
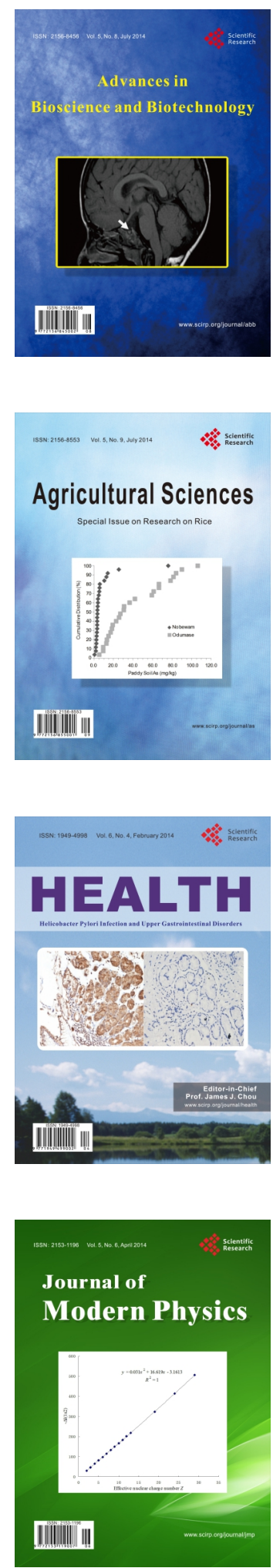
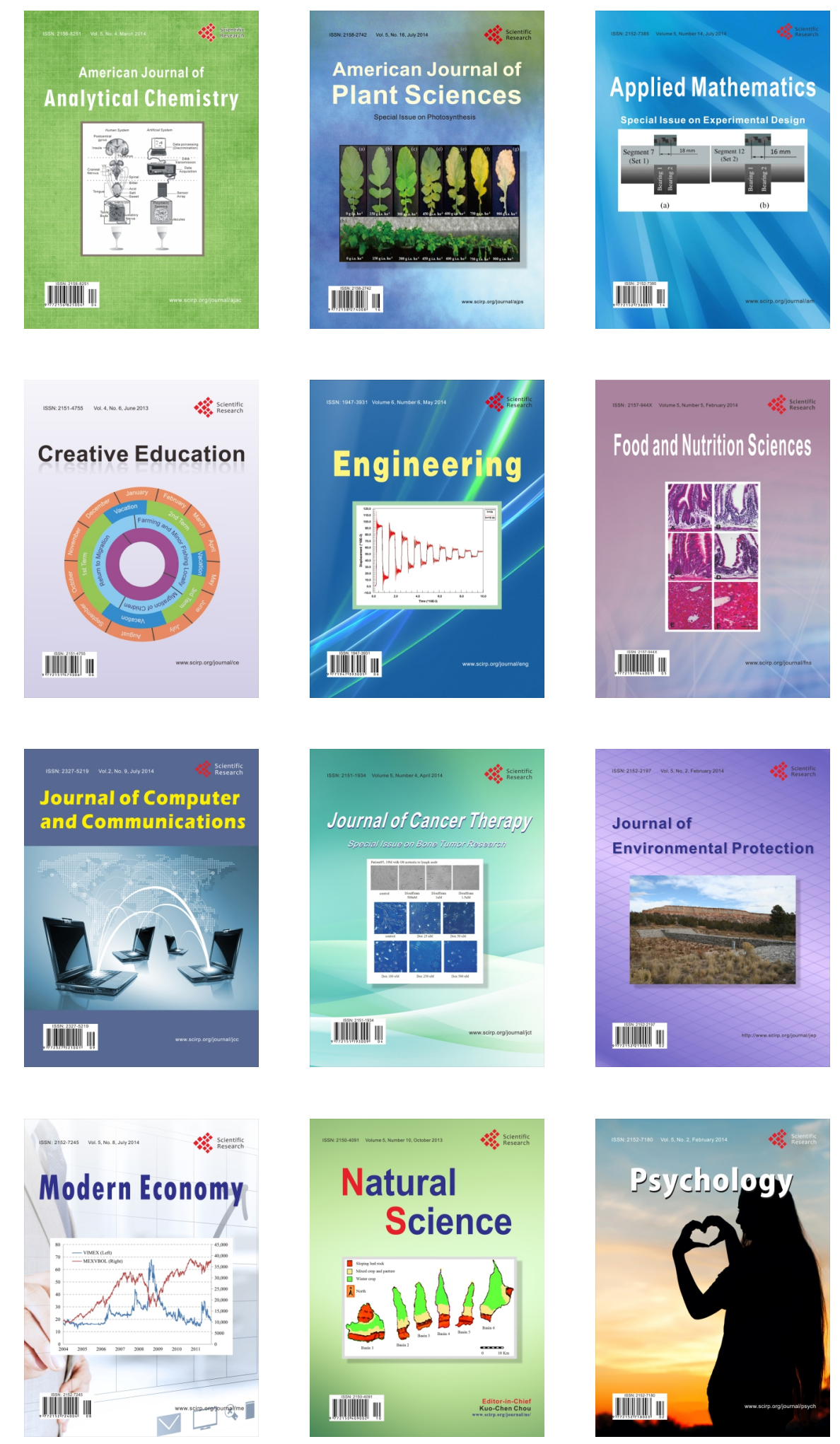